\title{
The push-out bond strength of calcium silicate-based endodontic sealers
}

\author{
David Donnermeyer ${ }^{1^{*}}$ D, Pia Dornseifer ${ }^{1}$, Edgar Schäfer $^{2}$ and Till Dammaschke ${ }^{1}$
}

\begin{abstract}
Background: The aim was to compare the dislodgement resistance of calcium silicate-based sealers (Total Fill BC Sealer, Endo CPM Sealer, BioRoot RCS) with an epoxy resin-based sealer (AH Plus).

Methods: The root canals of 80 single-rooted human teeth were instrumented with F360 up to size 45.04. All canals were obturated using matching gutta-percha cones according to the single-cone technique in combination with one of the mentioned sealers ( $n=20$ per group). After eight weeks of incubation $\left(37^{\circ} \mathrm{C}, 100 \%\right.$ humidity), the roots were embedded in resin. Starting with a distance of $7 \mathrm{~mm}$ from the apex, four slices of $1 \mathrm{~mm}$ thickness were cut. Dislodgement resistance was measured using a universal testing machine and the push-out bond strength was calculated. Specimens were examined under $4 \times$-magnification to determine the mode of bond failure. Statistical analysis was performed using ANOVA and Student-Newman-Keuls-test.
\end{abstract}

Results: Regarding the pooled data of all sections, the push-out bond strength of AH Plus was significantly higher than the push-out bond strength of all calcium silicate-containing sealers $(P<0.05)$. Out of all calcium silicate-based sealers, Total Fill BC Sealer showed the highest push-out bond strength $(P<0.05)$. BioRoot RCS had significant higher push-out bond strength than Endo CPM Sealer $(P<0.05)$. Nearly the same results were found for all four sections. BioRoot RCS only differed significantly from Endo CPM Sealer in the third section $(P<0.05)$.

Conclusions: The push-out bond strength of the investigated calcium silicate-based sealers was lower than of $\mathrm{AH}$ Plus. Total Fill BC showed the highest push-out bond strength of the calcium silicate-based sealers.

Keywords: BioRoot RCS, Calcium silicate-based sealer, Endo CPM sealer, Epoxy resin sealer, Push-out bond strength, Total fill BC sealer

\section{Background}

The connection between the root canal wall and the root canal filling core material is established by the endodontic sealer. A strong and long-lasting link between the root canal wall and the filling is one aspect of the prevention of root canal infection caused either by regrowth of microorganisms or newly gained infection due to coronal or apical leakage $[1,2]$. The bacteria-tight seal of the root canal established by the endodontic sealer is, therefore, a major aspect when evaluating the properties of different sealers [3]. Dislodgement resistance - also called push-out bond strength $(\mathrm{POBS})$ - is regarded as a relevant prognostic

\footnotetext{
* Correspondence: David.Donnermeyer@ukmuenster.de

${ }^{1}$ Department of Periodontology and Operative Dentistry, Westphalian Wilhelms-University, Albert-Schweitzer-Campus 1, building W 30, 48149 Münster, Germany

Full list of author information is available at the end of the article
}

factor to evaluate the link of a root canal sealer to the canal wall and the core material [4].

Endodontic sealers based on tricalcium silicate or containing calcium silicate formulations were recently introduced with a view to transferring the well-documented biocompatibility and bioactivity of di- and tricalcium silicate cements to root canal sealers. The release of calcium hydroxide from di- and tricalcium silicate cements due to hydration and the contact with phosphate from tissue fluids leads to a precipitation of calcium phosphate or calcium carbonate on the material's surface $[5,6]$. Also, the formation of hydroxyapatite on a calcium silicate sealer's surface after contact with phosphate has been reported [6]. This is the reason for the bioactive potential of tricalcium and dicalcium silicate materials and sealers [7]. Furthermore, calcium silicates form an interfacial layer at the dentin wall denoted as "mineral

(C) The Author(s). 2018 Open Access This article is distributed under the terms of the Creative Commons Attribution 4.0 International License (http://creativecommons.org/licenses/by/4.0/), which permits unrestricted use, distribution, and 
infiltration zone". The alkaline caustic effects of the calcium silicate cement's hydration products degrade the collagenous component of the interfacial dentin [8]. This degradation leads to the formation of a porous structure that facilitates the permeation of high concentrations of $\mathrm{Ca}^{2+}, \mathrm{OH}^{-}$, and $\mathrm{CO}_{3}{ }^{2-}$ ions, leading to increased mineralization in this region $[8,9]$. This chemical interaction at the interfacial dentin along with a micromechanical interaction by tag-like structures is mainly the reason for measurable adhesion between calcium silicate-based materials and dentin $[8,10]$.

Lately, different calcium silicate-based sealers were introduced. Total Fill BC Sealer (FKG, La Chaux-de-Fonds, Switzerland) is a monophasic sealer and contains calcium phosphate monobasic and tricalcium silicate. To allow setting, external fluid supply (e.g. tissue fluid) is required [11]. The formation of hydroxyapatite on its surface [12] has been reported. This sealer is also distributed under the brand names EndoSequence BC Sealer (BUSA, Savannah, USA) and iRoot SP (Innovative BioCeramix, Vancouver, Canada). Endo CPM Sealer (Egeo, Buenos Aires, Argentina) is another calcium silicate-based sealer. The powder mainly contains tricalcium silicate, tricalcium oxide, and tricalcium aluminate. The liquid consists of saline solution and calcium chloride [13]. Good sealing properties [13], as well as the ability to release calcium ions, have been reported [14]. BioRoot RCS (Septodont, St. Maur-des-Fossés, France) is the newest development of a bioceramic sealer. The powder mainly consists of tricalcium silicate, povidone, and zirconium dioxide. The liquid is an aqueous solution of calcium chloride with polycarboxylate [6]. Good biocompatibility was reported for Total Fill BC Sealer [15] and BioRoot RCS [15-18].

AH Plus (Dentsply, Konstanz, Germany) is a conventional epoxy resin-based root canal sealer and is widely used and well investigated $[2,19]$. Therefore, it was used as the control group in this study.

Though there is some data about the interfacial interaction between calcium silicate-based sealers and dentin, relevant data about the dislodgement resistance of calcium silicate-based sealers are currently only available for Total Fill BC Sealer. Only one study was found for Endo CPM Sealer concerning dislodgement resistance [20] and no data was available for BioRoot RCS. Therefore, the aim of this study was to evaluate the dislodgement resistance of Total Fill BC Sealer, Endo CPM Sealer, and BioRoot RCS under a clinical setup. The null hypotheses were:

(i) there are no differences between these calcium silicate-based sealers and the epoxy resin based sealer AH Plus regarding push-out bond strength (ii) there are no differences between these calcium silicate-based sealers and the epoxy resin based sealer AH Plus regarding the mode of failure.

\section{Methods}

Eighty human mandibular premolars with only one straight root canal (curvature $<5^{\circ}$ ) were included. All roots were observed with a stereomicroscope under 20x-magnification (Expert DN, Müller Optronic, Erfurt, Germany) to exclude cracks, caries or previous root canal treatment. Only single-rooted teeth with a single canal and a single apical foramen were included. This was verified by viewing their buccal and proximal radiographs. The radiographs were also used to check the curvature of the root canals using an imaging software (ImageJ, Wayne Rasband, NIH, MD, USA). The working length was obtained by measuring the length of the initial instrument (K-Files ISO 10 (VDW, Munich, Germany)) at the major apical foramen minus $1 \mathrm{~mm}$. All teeth were cut in a way that a working length of $18 \mathrm{~mm}$ was established. Patency of the canal was determined with K-files ISO 10 (VDW). Only teeth whose canal width near the terminus was approximately compatible with ISO 15 were included. This was examined with silver points ISO 15 and 20 (VDW). All root canals were instrumented with F360 files (Brasseler, Lemgo, Germany) using the torque-limited electric motor VDW.Silver (VDW) with the settings according to the manufacturer's instructions. The F360 file sequence was used up to size 45 with a constant taper of $4 \%$ in every root canal. The instruments were used in slow pecking motion with an amplitude of less than $3 \mathrm{~mm}$. The flutes of the instrument were cleaned after three in-and-out movements (pecks) and the root canal was irrigated with $2.5 \mathrm{ml} \mathrm{NaOCl} 3 \%$. After instrumentation, the canals were irrigated with $2.5 \mathrm{ml} \mathrm{NaOCl} 3 \%$ and $5 \mathrm{ml}$ EDTA $17 \%$ as the final irrigant to remove the smear layer using a $30 \mathrm{~g}$ open-ended needle (NaviTip, Ultradent, South Jordan, UT, USA). The needle was inserted as deep as possible into the canal without binding. Irrigation was performed with a volume of $1 \mathrm{ml}$ per minute. Finally, the canals were dried with paper points.

The specimens were randomly divided into four groups $(n=20)$. Root canals of all groups were obturated using matching F360 gutta-percha cones size 45.04 (Brasseler). The following groups were established: Group A: Total Fill BC Sealer; Group B: Endo CPM Sealer; Group D: BioRoot RCS; control Group D: AH Plus. All sealers were mixed according to the manufacturers' instructions and were applied with a 20G intracanal tip (Transcodent, Kiel, Germany) from a syringe into the canal to ensure homogeneous obturation. Root canal obturation was performed according to the single-cone technique using gutta-percha cones matching the F360 
system. Before inserting the gutta-percha cone into the root canal, it was covered with sealer. Following obturation, a heated plugger was used to remove the coronal excess gutta-percha with no further vertical compaction. The teeth were radiographed in buccal and proximal view to verify correct obturation. The canal orifices were restored with Cavit G (3 M ESPE, Seefeld, Germany). The teeth were stored in an incubator at $37{ }^{\circ} \mathrm{C}$ and $100 \%$ humidity for 2 months as it is known that the setting reaction of calcium silicate cement might continue for $21 \mathrm{~d}$ [21] to more than a month [22]. All treatment procedures were carried out by the same operator who was proficient in the obturation technique used.

The roots were embedded into acrylic resin vertically (Technovit 4071, Heraeus Kulzer, Hanau, Germany) and sectioned horizontally with a $0.25 \mathrm{~mm}$-low-speed saw (Leitz, Wetzlar, Germany) under permanent water-cooling between a distance of $7.00 \mathrm{~mm}$ and $11.75 \mathrm{~mm}$ from the apex (Table 1). Thus, four slices of $1 \mathrm{~mm}$ thickness were obtained representing the middle third of the root. This resulted in a total of 80 specimens per group. The sample size was calculated with a power calculation for one-way ANOVA (power $=0.8$; effect size $=0.25$; significance level $=0.05$; number of groups $=4$ ) resulting in recommended sample size of minimum 44.6 samples per group. In the case that sectioning of the teeth revealed an oval canal, a canal with isthmuses, or voids in the obturation the whole set of four specimens per root was discarded and replaced by a new set which was gained from an additionally enclosed tooth. This occurred in only 3 teeth.

For the dislodgement resistance measurement and mode of failure evaluation, the specimens were coded by the supervisor, who was the only person being aware of the allocation of the coded specimens to the groups. The specimens were placed in a metallic jig with a hole underneath to allow the canal filling material to fall from the canal after dislodgement. A standard size plunger with a tip of $0.6 \mathrm{~mm}$ diameter was used to apply the vertical load onto the gutta-percha core of the filling. The diameter of the plunger tip was dimensioned according to the gutta-percha point diameter at $6 \mathrm{~mm}$ from the tip to ensure an equal distribution of the load on $60 \%$ to $85 \%$ of the gutta-percha cone diameter without touching the sealer phase of the root canal filling. The vertical load was applied in an apical to coronal direction and generated by a universal testing machine (Lloyd LF Plus, Ametek, Berwyn, Pennsylvania, USA) at a speed of $1 \mathrm{~mm}$ per minute. A graph of the applied load was generated by a software (Nexygen, Ametek, Berwyn, Pennsylvania, USA) and failure of the bond was automatically determined when the graph showed an abrupt reduction of load. This failure load was recorded in Newton (N).

The lateral surface of the root canal of each specimen was calculated by the truncated cone formula $M=(R+r) \cdot \pi \cdot m$. The push-out bond strength of each specimen was then calculated and expressed in $\mathrm{N} / \mathrm{mm}^{2}$ (equivalent to $\mathrm{MPa}$ ).

After dislodgement of the root canal filling photographs of each specimen were taken with a laser microscope (VK-X100, Keyence, Osaka, Japan) under 4x-magnification. The photographs were separately evaluated by two blinded operators and the mode of failure was recorded. If disagreement existed a joint meeting of all authors was made until a consensus was reached. There were three possible categories: adhesive failure (no material left on canal wall), cohesive failure (material present on entire canal wall) and mixed failure (material in patches on canal wall) (Fig. 1).

Statistical analysis of POBS values was performed using ANOVA and Student-Newman-Keuls-post-hoc-test $(p<0.05)$ as data were distributed normally according to the Kolmogorov-Smirnov test $(p<0.05)$.

\section{Results}

All specimens had measurable adhesion to the root dentin and no premature failure occurred. Pooling the data of the four sections, AH Plus revealed significantly higher dislodgement resistance than all calcium silicate-based sealers $(p<0.05)$. Among the calcium silicate-containing sealers Total Fill BC Sealer showed the highest push-out bond strength values $(p<0.05)$. BioRoot RCS produced significantly higher POBS values than Endo CPM Sealer $(p<0.05)$ (Table 1).

Table 1 Push-out Bond Strength of all sealers tested in $\mathrm{N} / \mathrm{mm}^{2}$

\begin{tabular}{|c|c|c|c|c|c|c|c|c|c|c|}
\hline & \multicolumn{2}{|l|}{ Overall } & \multicolumn{2}{|c|}{$\begin{array}{l}\text { Section "Background" } \\
\text { (10.75-11.75 mm from apex) }\end{array}$} & \multicolumn{2}{|c|}{$\begin{array}{l}\text { Section "Methods" } \\
(9.5-10.5 \text { mm from apex) }\end{array}$} & \multicolumn{2}{|c|}{$\begin{array}{l}\text { Section "Results" } \\
\text { (8.25-9.25 mm from apex) }\end{array}$} & \multicolumn{2}{|c|}{$\begin{array}{l}\text { Section "Discussion" } \\
\text { (7.0-8.0 mm from apex) }\end{array}$} \\
\hline & Mean & $\mathrm{SD}$ & Mean & SD & Mean & SD & Mean & $\mathrm{SD}$ & Mean & SD \\
\hline Total Fill BC Sealer & $3.52^{\mathrm{b}}$ & 1.41 & $2.95^{\mathrm{b}}$ & 1.06 & $3.84^{b}$ & 1.49 & $3.42^{b}$ & 0.92 & $3.89^{b}$ & 1.88 \\
\hline Endo CPM Sealer & $1.60^{d}$ & 0.83 & $1.58^{\mathrm{C}}$ & 0.75 & $1.53^{\mathrm{C}}$ & 0.94 & $1.47^{\mathrm{d}}$ & 0.79 & $1.82^{c}$ & 0.85 \\
\hline BioRoot RCS & $2.31^{\mathrm{c}}$ & 1.31 & $1.96^{\mathrm{c}}$ & 1.20 & $2.08^{c}$ & 1.25 & $2.76^{\mathrm{c}}$ & 1.30 & $2.44^{\mathrm{c}}$ & 1.43 \\
\hline AH Plus & $7.03^{a}$ & 2.41 & $6.12^{\mathrm{a}}$ & 1.48 & $6.37^{\mathrm{a}}$ & 1.74 & $7.01^{\mathrm{a}}$ & 1.80 & $8.62^{a}$ & 3.42 \\
\hline
\end{tabular}

SD standard deviation. Values with different superscript letters in each column were statistically different at $p=0.05$ (ANOVA and Student-Newman-Keuls test) 


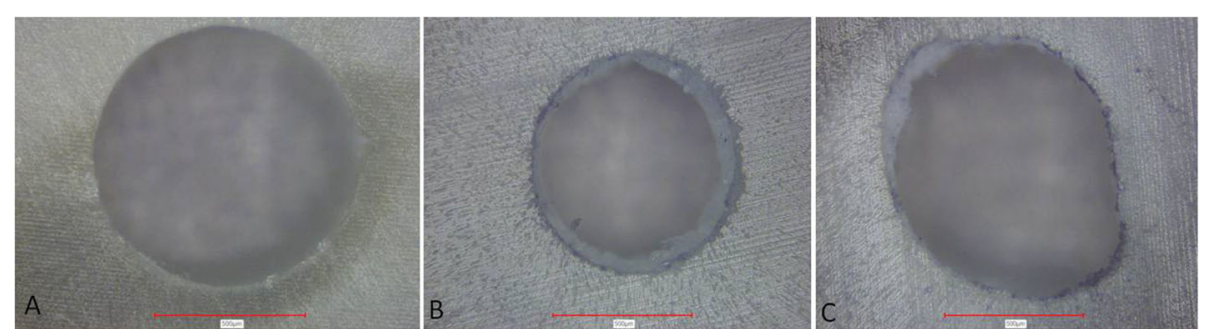

Fig. 1 Images obtained by laser microscopy at 4X-magnification for analysis of the mode of failure; examples for adhesive (a), cohesive (b) and mixed (c) failure types are given

With regards to the different sections (Table 1), Total Fill BC Sealer showed significantly higher POBS values in the first, in the second and in the fourth section than BioRoot RCS and Endo CPM Sealer $(p<0.05)$ while no significant differences were found between BioRoot RCS and Endo CPM Sealer $(p>0.05)$. The third section revealed the same results as the overall results.

The results of the mode of failure analysis are shown in Table 2 and Fig. 2. AH Plus and Total Fill BC Sealer predominantly showed cohesive failure modes whereas BioRoot RCS and Endo CPM Sealer mainly displayed mixed failure modes. For BioRoot RCS and Endo CPM Sealer adhesive failure was the second most common failure mode.

\section{Discussion}

A selection of calcium silicate based sealers was investigated for their POBS and failure mode during dislodgement. The push-out test has been widely used to evaluate the dislodgement resistance of root canal filling materials [23]. Statistically significant differences were found between $\mathrm{AH}$ Plus and the calcium silicate based sealers. None of the calcium silicate based sealers reached the dislodgement resistance of AH Plus (Table 1). Furthermore, statistically significant differences were found between the calcium silicate based sealers. Differences in the mode of failure were found between AH Plus and some of the calcium silicate-based sealers as well as between the calcium silicate-based sealers. Thus, the null hypotheses (i) and (ii) were rejected.

The investigation of POBS is a commonly used approach to evaluate the dislodgement resistance of a

Table 2 Mode of Failure during dislodgement of all sealers tested (in \%)

\begin{tabular}{llll}
\hline Sealer & \multicolumn{2}{l}{ Mode of failure } & \\
\cline { 2 - 4 } & Adhesive & Mixed & Cohesive \\
\hline Total Fill BC Sealer & 4.4 & 32.5 & 63.1 \\
Endo CPM Sealer & 13.1 & 77.5 & 9.4 \\
BioRoot RCS & 18.1 & 70.6 & 11.2 \\
AH Plus & 8.1 & 31.9 & 60.0 \\
\hline
\end{tabular}

sealer. Within the limitations of the POBS investigation, the bond of the sealer either to the root canal wall or to the core material is assessed with the interaction of a sealer with root dentin being an extraordinarily important factor for the success of endodontic procedures [24]. Although widely used, many different testing protocols have been established [25]. The most crucial step of the experimental setup is the ratio of the pin diameter and the specimen's diameter $[4,24]$. A ratio of less than 0.6 was reported to influence the POBS in both studies. Chen et al. [24] also mentioned that a ratio higher than 0.85 may influence the POBS test, which could not be approved by Pane et al. [3]. In the present study, the pin diameter was designed to be within this range. Moreover, different experimental protocols that were established in the past concerning root canal preparation (diameter and taper), root canal obturation (cold versus warm obturation techniques), the tooth type and portion, slice thickness, load velocity, and other parameters can be an explanation for the variability in results [23, 26]. In the present study, a reproducible instrumentation was sought by a preparation up to size 45 with a continuous taper of .04. Regarding obturation techniques, lateral compaction and warm vertical compaction may exert a certain impact on the dislodgement resistance $[27,28]$ and are less reproducible than the single-cone technique. Therefore, the single-cone obturation using matching gutta-percha cones was performed in the present study. Recently, a standardization of the push-out test was demanded to investigate special questions regarding the sealer-dentin-interface. In these studies, the root canal filling was established without the use of a core material such as gutta-percha [28, 29]. Despite a possible confounding factor due to the use of a core material, the present study was designed to provide information about the dislodgement resistance of calcium silicate-based sealers in a clinically orientated setup. Therefore, the sealers were used in a manner that is recommended by the manufacturer and commonly used by clinicians.

In accordance with the present data superior POBS has been reported for AH Plus compared to calcium 


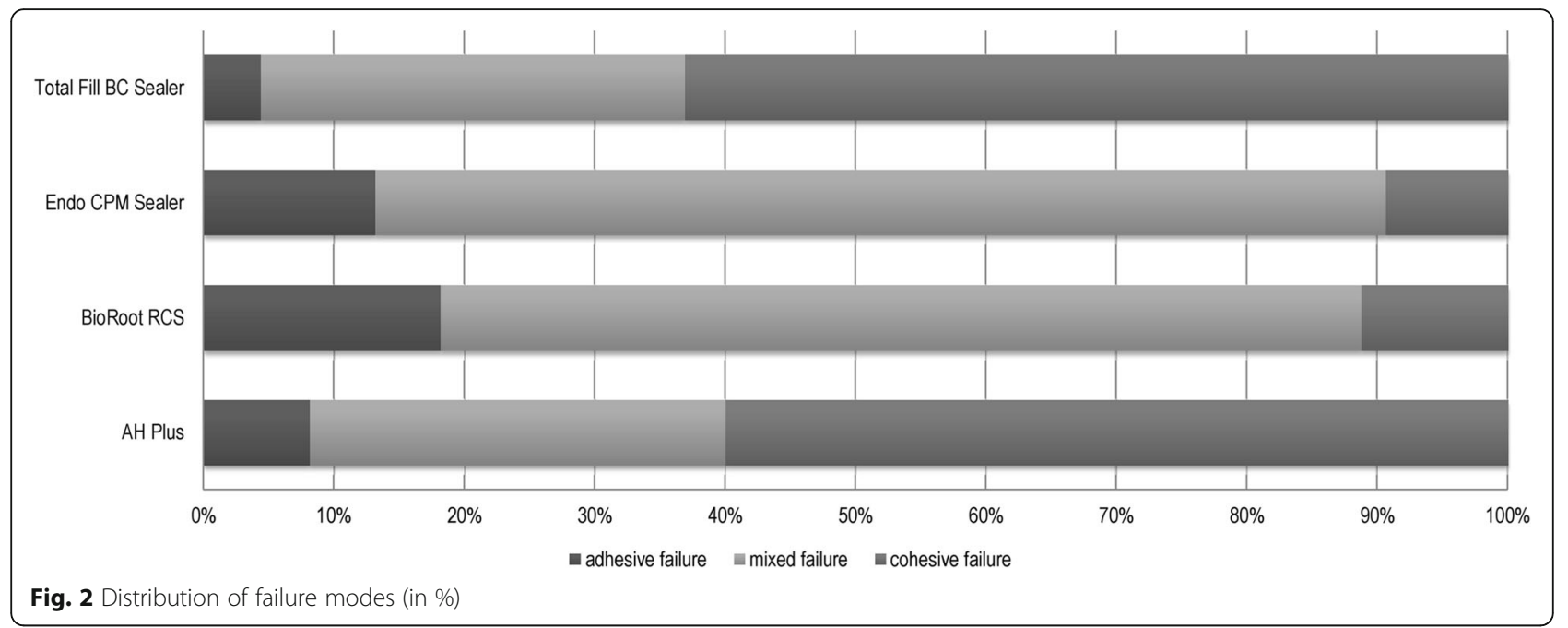

silicate-based sealers [20, 26, 30-34]. POBS values differ depending on the different protocols (preparation taper, obturation technique, plunger dimensions) used in these studies and are therefore not comparable. Total Fill BC Sealer has been reported to possess inferior POBS compared to AH Plus [26, 30-32], which corroborates the results of the present study. However, another study reported no differences regarding the POBS of AH Plus and Total Fill BC Sealer [33]. In summary, the present results are in major compliance with the current data. In contrast to the present study, Endo CPM Sealer achieved higher POBS values than AH Plus in another investigation [20]. In that study, root canal preparation was performed with a taper of only $2 \%$ and obturation was performed by lateral compaction [20]. These differences in the experimental setup might be an explanation for the contradictory findings. No further data regarding the dislodgement resistance of Endo CPM Sealer are currently available. For BioRoot RCS no data regarding POBS have been published yet. In the present study, BioRoot RCS showed inferior POBS than AH Plus and Total Fill BC Sealer, but superior values compared to Endo CPM Sealer.

On the basis of the data available it can be concluded that $\mathrm{AH}$ Plus has high resistance to dislodgement in general. The covalent bonds between the epoxy resin and the amino groups of the dentinal collagen [35, 36] may result in a stronger link of AH Plus to dentin compared to the interaction of calcium silicates to dentin. The micromechanical interaction between the root canal wall and the calcium silicate based sealer by the tag-like structures and the chemical interaction by the "mineral infiltration zone" [8] establish a weaker link to the dentin compared to epoxy resins. This observation also corroborates the clinically orientated findings, that the retreatment of calcium silicate-based sealers is more efficient than of epoxy resin sealers [37]. Still, the reason for the differences in the dislodgement resistance between the different calcium silicate-based sealer formulations is questionable. It is evident that the different compositions are related to differences in the interaction to root dentin. In the present study, a monophasic calcium silicate-based sealer showed favorable results.

With regard to the mode of failure, the present results obtained for Total Fill BC Sealer are in accordance with previously reported findings [32, 38]. Further comparisons with other investigations are not possible as either the mode of failure was not reported in studies on dislodgement resistance or the experimental setup differed from the methodology used in the present study. AH Plus and Total Fill BC Sealer predominantly showed cohesive failure modes. When considering that BioRoot RCS and Endo CPM Sealer mainly displayed mixed failure modes it is evident that higher POBS are correlated with predominantly cohesive failure modes whereas lower POBS are associated with mixed failure modes. Furthermore, it is likely that the link between epoxy resin sealers and gutta-percha is weaker than the link to dentin which can be concluded from the higher proportion of cohesive failures in the AH Plus group. The same conclusion can be made for Total Fill BC Sealer. Regarding the greater proportion of mixed failures with BioRoot RCS and Endo CPM Sealer, it can be presumed that the link between these sealers to dentin is comparable to the link to gutta-percha. The lesser proportion of adhesive failures in all groups gives evidence for a mechanism of adhesion of calcium silicate-based sealers to root canal dentin (Fig. 2).

To the best of our knowledge, the present study provides first information concerning the dislodgement resistance of BioRoot RCS. It also extends the knowledge about the dislodgement resistance of calcium silicate-based 
sealer under clinically relevant conditions. Regarding the different POBS values of the calcium silicate-based sealers, further evaluation of these sealers under experimental and clinical conditions is required.

\section{Conclusion}

Within the limitations of this study (extracted teeth, age of patient, in-vitro study), the push-out bond strength of the investigated calcium silicate-based sealers was lower than the push-out bond strength of AH Plus. Total Fill $\mathrm{BC}$ showed the highest push-out bond strength of the calcium silicate-based sealers. BioRoot RCS displayed higher push-out bond strength than Endo CPM Sealer.

\section{Abbreviation}

POBS: Push-out bond strength

\section{Availability of data and materials}

The dataset used and/or analyzed during the current study are available from the corresponding author on reasonable request.

\section{Author's contributions}

All authors have contributed significantly to this work and contributed to the paper in equal parts. DD had the idea for the research and developed the concept, participated in the in vitro experiments, literature research, writing the manuscript and carried out proofreading. PD performed the in vitro experiments, participated in literature research and carried out proofreading. ES participated in the design of the study, in literature research, writing of the manuscript, performed the statistical analysis and carried out proofreading. TD participated in study development, literature research, writing of the manuscript and carried out proofreading. All authors read and approved the final manuscript. All authors are in agreement with the content of the manuscript.

\section{Ethics approval and consent to participate}

Not applicable.

\section{Consent for publication}

Not applicable.

\section{Competing interests}

We acknowledge support by Open Access Publication Fund of University of Muenster. The authors declare that they have no competing interests.

\section{Publisher's Note}

Springer Nature remains neutral with regard to jurisdictional claims in published maps and institutional affiliations.

\section{Author details}

${ }^{1}$ Department of Periodontology and Operative Dentistry, Westphalian Wilhelms-University, Albert-Schweitzer-Campus 1, building W 30, 48149 Münster, Germany. ${ }^{2}$ Central Interdisciplinary Ambulance in the School of Dentistry, Albert-Schweitzer-Campus 1, building W 30, 48149 Münster, Germany.

Received: 2 March 2018 Accepted: 13 August 2018

Published online: 20 August 2018

\section{References}

1. Wu MK, Fan B, Wesselink PR. Diminished leakage along root canals filled with gutta-percha without sealer over time: a laboratory study. Int Endod J. 2000;33:121-5

2. Whitworth J. Methods of filling root canals: principles and practices. Endod Topics. 2005;12:2-24

3. Khalil I, Naaman A, Camilleri J. Properties of Tricalcium silicate sealers. J Endod. 2016; https://doi.org/10.1016/j.joen.2016.06.002.
4. Pane ES, Palamara JE, Messer HH. Critical evaluation of the push-out test for root canal filling materials. J Endod. 2013;39:669-73.

5. Sarkar NK, Caicedo R, Ritwik P, Moiseyeva R, Kawashima I. Physicochemical basis of the biologic properties of mineral trioxide aggregate. J Endod. 2005;31:97-100.

6. Prüllage RK, Urban K, Schäfer E, Dammaschke T. Material properties of a tricalcium silicate-containing, a mineral trioxide aggregatecontaining, and an epoxy resin-based root canal sealer. J Endod. 2016:42:1784-8.

7. Torabinejad M. Calcium silicate-based cements. In: Torabinejad M, editor. Mineral trioxide aggregate: properties and clinical applications. Ames: Wiley Blackwell; 2014. p. 281-332.

8. Atmeh AR, Chong EZ, Richard G, Festy F, Watson TF. Dentin-cement interfacial interaction: calcium silicates and polyalkenoates. J Dent Res. 2012;91:454-9.

9. Watson TF, Atmeh AR, Sajini S, Cook RJ, Festy F. Present and future of glass ionomers and calcium-silicate cements as bioactive materials in dentistry: biophotonics-based interfacial analyses in health and disease. Dent Mater. 2014;30:50-61

10. Kaup M, Dammann C, Schäfer E, Dammaschke T. Shear bond strength of biodentine, ProRoot MTA, glass ionomer cement and composite resin on human dentine ex vivo. Head Face Med. 2015;19:11-4.

11. Xuereb M, Vella P, Damidot D, Sammut CV, Camilleri J. In situ assessment of the setting of tricalcium silicate-based sealers using a dentin pressure model. J Endod. 2015;41:111-24.

12. Han L, Okiji T. Bioactivity evaluation of three calcium silicate-based endodontic materials. Int Endod J. 2013;46:808-14.

13. Orosco FA, Bramante CM, Garcia RB, Bernadineli N, Moraes IG. Sealing ability of gray MTA AngelusTM, CPM TM and MBPC used as apical plugs. J Appl Oral Sci. 2008:16:50-4

14. Tanomaru-Filho M, Chaves Faleiros FB, Sacaki JN, Hungaro Duarte MA Guerreiro-Tanomaru JM. Evaluation of $\mathrm{pH}$ and calcium ion release of rootend filling materials containing calcium hydroxide or mineral trioxide aggregate. J Endod. 2009;35:1418-21.

15. Poggio C, Riva P, Chiesa M, Colombo M, Pietrocola G. Comparative cytotoxicity evaluation of eight root canal sealers. J Clin Exp Dent. 2017:9:e574-8

16. Camps J, Jeanneau C, El Ayachi I, Laurent P, About I. Bioactivity of a calcium silicate-based endodontic cement (BioRoot RCS): interactions with human periodontal ligament cells in vitro. J Endod. 2015;41:1469-73.

17. Dimitrova-Nakov S, Uzunoglu E, Ardila-Osorio H, Baudry A, Richard G, Kellermann O, et al. In vitro bioactivity of BioRoot RCS, via A4 mouse pulpal stem cells. Dent Mater. 2015;31:1290-7.

18. Eldeniz AU, Shehata M, Hoegg C, Reichl FX. DNA double-strand breaks caused by new and contemporary endodontic sealers. Int Endod J. 2016:49:1141-51.

19. Hergt A, Wiegand A, Hülsmann M, Rödig T. AH plus root canal sealer - an updated literature review. ENDO. 2015;9:245-65.

20. Assmann E, Scarparo RK, Böttcher DE, Grecca FS. Dentin bond strength of two mineral trioxide aggregate-based and one epoxy resin-based sealers. J Endod. 2012:38:219-21.

21. Gancedo-Caravia L, Garcia-Barbero E. Influence of humidity and setting time on the push-out strength of mineral trioxide aggregate obturations. J Endod. 2006;32:894-6.

22. Chedella SCV, Berzins DW. A differential scanning calorimetry study of the setting reaction of MTA. Int Endod J. 2010;43:509-18.

23. Collares FM, Portella FF, Rodrigues SB, Celeste RK, Leitune VC, Samuel SM. The influence of methodological variables on the push-out resistance to dislodgement of root filling materials: a meta-regression analysis. Int Endod J. 2015; https://doi.org/10.1111/iej.12539.

24. Chen WP, Chen YY, Huang SH, Lin CP. Limitations of push-out test in bond strength measurement. J Endod. 2013;39:283-7.

25. Neelakantan P, Ahmed HMA, Wong MCM, Matinlinna JP, Cheung GSP. Effect of root canal irrigation protocols on the dislocation resistance of mineral trioxide aggregate-based materials: a systematic review of laboratory studies. Int Endod J. 2018; https://doi.org/10.1111/iej.12898.

26. Oliveira DS, Cardoso ML, Queiroz TF, Silva EJ, Souza EM, De-Deus G. Suboptimal push-out bond strengths of calcium silicate-based sealers. Int Endod J. 2016:49:796-80

27. Gade VJ, Belsare LD, Patil S, Bhede R, Gade JR. Evaluation of push-out bond strength of endosequence $B C$ sealer with lateral condensation 
and thermoplasticized technique: an in vitro study. Conserv Dent. 2015;18:124-7.

28. Mokhtari H, Rahimi S, Forough Reyhani M, Galledar S, Mokhtari Zonouzi HR. Comparison of push-out bond strength of gutta-percha to root canal dentin in single-cone and cold lateral compaction techniques with $\mathrm{AH}$ plus sealer in mandibular premolars. J Dent Res Dent Clin Dent Prospects. 2015;9:221-5

29. do Carmo SS, FFP N, Bachmann L, CES M, LMS C-R, Oliveira IR, Raucci-Neto W. Influence of early mineral deposits of silicate- and aluminate-based cements on push-out bond strength to root dentine. Int Endod J. 2017; https://doi.org/10.1111/iej.12791.

30. Carvalho NK, Prado MC, Senna PM, Neves AA, Souza EM, Fidel SR, et al. Do smear-layer removal agents affect the push-out bond strength of calcium silicate-based endodontic sealers? Int Endod J. 2017;50:612-9.

31. Amin SAW, Seyam RS, El-Samman MA. The effect of prior calcium hydroxide intracanal placement on the bond strength of two calcium silicate-based and an epoxy resin-based endodontic sealer. J Endod. 2012;38:696-9.

32. Carvalho CN, Grazziotin-Soares R, de Miranda Candeiro GT, Gallego Martinez $L$, de Souza JP, Santos Oliveira P, et al. Micro push-out bond strength and bioactivity analysis of a bioceramic root canal sealer. Iran Endod J. 2017;12:343-8.

33. Sagsen B, Ustun Y, Demirbuga S, Pala K. Push-out bond strength of two new calcium silicate-based endodontic sealers to root canal dentine. Int Endod J. 2011;44:1088-91.

34. Gokturk H, Bayram E, Bayram HM, Aslan T, Ustun Y. Effect of double antibiotic and calcium hydroxide pastes on dislodgement resistance of an epoxy resin-based and two calcium silicate-based root canal sealers. Clin Oral Invest. 2017;21:1277-82.

35. Fisher MA, Berzins DW, Bahcall JK. An in vitro comparison of bond strength of various obturation materials to root canal dentin using a push-out test design. J Endod. 2007;33:856-8.

36. Neelakantan P, Sharma S, Shemesh H, Wesselink PR. Influence of irrigation sequence on the adhesion of root canal sealers to dentin: a Fourier transform infrared spectroscopy and push-out bond strength analysis. J Endod. 2015:41:1108-11.

37. Donnermeyer D, Bunne C, Schäfer E, Dammaschke T. Retreatability of three calcium silicate-containing sealers and one epoxy resin-based root canal sealer with four different root canal instruments. Clin Oral Investig. 2018;22:811-7

38. Shokouhinejad N, Gorjestani H, Nasseh AA, Hoseini A, Mohammadi M, Shamshiri AR. Push-out bond strength of gutta-percha with a new bioceramic sealer in the presence or absence of smear layer. Aust Endod J. 2013:39:102-6

\section{Ready to submit your research? Choose BMC and benefit from:}

- fast, convenient online submission

- thorough peer review by experienced researchers in your field

- rapid publication on acceptance

- support for research data, including large and complex data types

- gold Open Access which fosters wider collaboration and increased citations

- maximum visibility for your research: over $100 \mathrm{M}$ website views per year

At BMC, research is always in progress.

Learn more biomedcentral.com/submissions 